American Journal of Biological and Environmental Statistics
2018; 4(1): 1-9
http://www.sciencepublishinggroup.com/j/ajbes
doi: 10.11648 /j.ajbes.20180401.11
ISSN: $2471-9765$ (Print); ISSN: $2471-979 \mathrm{X}$ (Online)

\title{
Climate Variability and Small-Scale Farmer Adaptation Strategy in Setema-Gatira Area of Jimmaa, Southwestern Ethiopia
}

\author{
Girma Eshetu $^{1, *}$, Tino Johansson ${ }^{2,3}$, Wayessa Garedew ${ }^{4}$, Tigist Yisihak ${ }^{5}$ \\ ${ }^{1}$ Ethiopian Biodiversity Institute (EBI), Harar Biodiversity Center, Harar, Ethiopia \\ ${ }^{2}$ Chiesa Project Coordinator at International Insect Physiology and Ecology, Nairobi, Kenya \\ ${ }^{3}$ Department of Geosciences and Geography, University of Helsinki, Helsinki, Finland \\ ${ }^{4}$ College of Agriculture and Veterinary Medicine, Jimma University, Jimma, Ethiopia \\ ${ }^{5}$ Department of Horticulture, Wolayeta Sodo University, Sodo, Ethiopia
}

Email address:

Girma.eshetu@ymail.com (G. Eshetu)

${ }^{*}$ Corresponding author

\section{To cite this article:}

Girma Eshetu, Tino Johansson, Wayessa Garedew, Tigist Yisihak. Climate Variability and Small-Scale Farmer Adaptation Strategy in Setema-Gatira Area of Jimmaa, Southwestern Ethiopia. American Journal of Biological and Environmental Statistics.

Vol. 4, No. 1, 2018, pp. 1-9. doi: 10.11648/j.ajbes.20180401.11

Received: November 24, 2017; Accepted: December 11, 2017; Published: January 9, 2018

\begin{abstract}
This study examines rainfall trends, variability and small-scale farmer adaptation strategies to climate change in setema-Gatira area of Jimma, Southwestern Ethiopia. In this study, the trends and variability of rainfall were analyzed for Setema and Gatira meteorological stations. Daily rainfall data for two stations were obtained from National Meteorological Agency of Ethiopia. Mann-Kendall's test was employed for a rainfall trend analysis. Standardized rainfall anomaly index, rainfall concentration index and coefficient of variation were used as descriptors of rainfall variability. The coping mechanism was analyzed using means and frequency. The trend analysis revealed decreasing rainfall trend in Setema and increasing trend in Gatira. However, rainfall trends were not statistically significant $(\mathrm{p}<0.05)$. The coefficient variation of the study area for Setema was $(\mathrm{CV}=23 \%)$, while for Gatira it was $(\mathrm{CV}=8 \%)$ which showed lower inter-annual variability. The rainfall concentration index revealed that $35 \%$ of years with values of PCI $>16$ in setema which indicate poor monthly distribution. Monthly rainfall concentration range from moderate to high and total rainfall of the study area concentrated in $1 / 2$ of the period. The standardized anomalies of annual rainfall revealed negative anomalies $42 \%$ at Setema and $50 \%$ of years at Gatira. All most in all stations annual rainfall has shown negative anomalies for much of the 1983/4 and 1994. Selling livestock and changing farming practices was the major response to climate variability in the area. Present study only showed local level rainfall trend and variability analysis, so future study should include watershed or regional levels.
\end{abstract}

Keywords: Climate Change Adaptation, Rainfall Trend, Standard Anomaly Index, Precipitation Concentration Index

\section{Introduction}

Climate variability and change are among the major environmental challenges of the 21 st century [21]. Today, there is strong evidence and understanding that climate change is happening and it is recognized as being one of the greatest challenges of our century. Climate change affects with increased average annual temperatures, reduced and increased variability in rainfall reduces crop yield and threatens food security in low-income and agriculture-based economies [16]. Intergovernmental Panel on Climate Change confirmed a change in precipitation is due to climate change. However, Change in rainfall and temperature are not globally uniform [21]. Regional variations can be much larger, and considerable spatial and temporal variations may exist between climatically different stations.

Agriculture is the most dominant sector of Ethiopia economy contributing $42-45 \%$ of GDP and $80 \%$ of 
employment [6]. Despite its significant contribution to national economy, the sector is challenged mainly by climate-related disaster. According to World Bank [23], report drought and flood are very common climate changerelated hazards in Ethiopia, with significant drought events occurring every 3 to 5 years. The main source of water for the sector is natural rainfall, so any change in rainfall amount and distribution lead to serious production deficit [5]. In this regard, knowing the variations in the general rainfall pattern is vital to understand the climate change variations and its consequence on ecosystem [12].

Precipitation trend analysis, on different spatial and temporal scales, has been of great concern during the past century because of the attention is given to global climate change by the scientific community. Assessing rainfall trends and variability is paramount to understand the variations in space and time. The Intergovernmental Panel on Climate Change suggested that detail analysis of local precipitation variability. In Ethiopia, several studies have been carried out on rainfall and temperature trend and variability analysis based on historical data of some selected weather stations [3], [2], [4] and over whole the country [19], [17] and [11]. Among the studies, national meteorology agency [19] reported that annual rainfall remained more or less constant when averaged over the whole country. However, mean annual temperature in Ethiopia has increased by $1.3^{\circ} \mathrm{C}$ between 1960 and 2006 , at an average rate of $0.28^{\circ} \mathrm{C}$ per decade increased [17]. On other hand Wing et al. [25] Report shows a significant decline in main season (June to September) rainfall was recorded in the southwestern and central parts of Ethiopia. Similar, Baley [3] findings revealed declined rainfall in the central rift valley of Ethiopia. It is very difficult to detect long-term rainfall trends in Ethiopia, due to the high inter-annual and inter-decadal rainfall variability. Assessing trends and variability in rainfall based on past records help better understanding of problem associated with drought, floods and water various uses [8]. Moreover, it also essential to develop adaptation strategies and for planning agricultural activity [1] The present study has provided an assessment of rainfall trends and variability in Setema-Ageyo districts of Jimma southwestern Ethiopia.

\section{Research Methodology}

\subsection{Study Area Descriptions}

The research was conducted in two districts of Oromia region (Setema and Gumay) in the southwestern, Ethiopia. Geographyically the study area is located between $8^{\circ} 4^{\prime}-8^{\circ}$ 2 ' North latitude and $30^{\circ} 20^{\prime}-30^{\circ} 28^{\prime}$ East longitude. The study area located at about 450 kilometers away from Addis Ababa, the capital city of Ethiopia and $100 \mathrm{~km}$ in North West of Jimma town. The altitudinal range of the study district is between 1450 and 2400 meters above sea level (m.a.s.l). These two districts were selected because of the availability of long-term meteorological data. The mean annual rainfall in the study area is $1665 \mathrm{~mm} /$ year. Western and southwestern parts of the country experience a unimodal rainfall pattern. October to January (Birra) denotes the time when the long rainfall season comes to an end to be followed by a medium to the short dry season during the same period. February to May (Bona) is the start of the long rainy season. Over the western parts of the country also the rainy season starts during March/April. June to September (Main season) is a long and heavy summer rain, normally called the big rain or Gannaa, which falls from June-September [26]. Study area annual average maximum temperature is $27.9^{\circ} \mathrm{C}$ and minimum temperature is $11.9^{\circ} \mathrm{C}$. Change in time/quantity of seasonal and annual rainfall is important factors in the agriculture activities of the study areas.

Agriculture is the main economic activities and dominated by small-scale and mixed crop and livestock farmers. Crop production is mainly rain-fed. Coffee plays a major role in income generation in the areas. Maize, Teff (Eragrostis teff) and sorghum (Sorghum bicolor) are the major crops grown in the area. Pulses crops, such as beans and pea are grown to a lesser extent in the area [9].

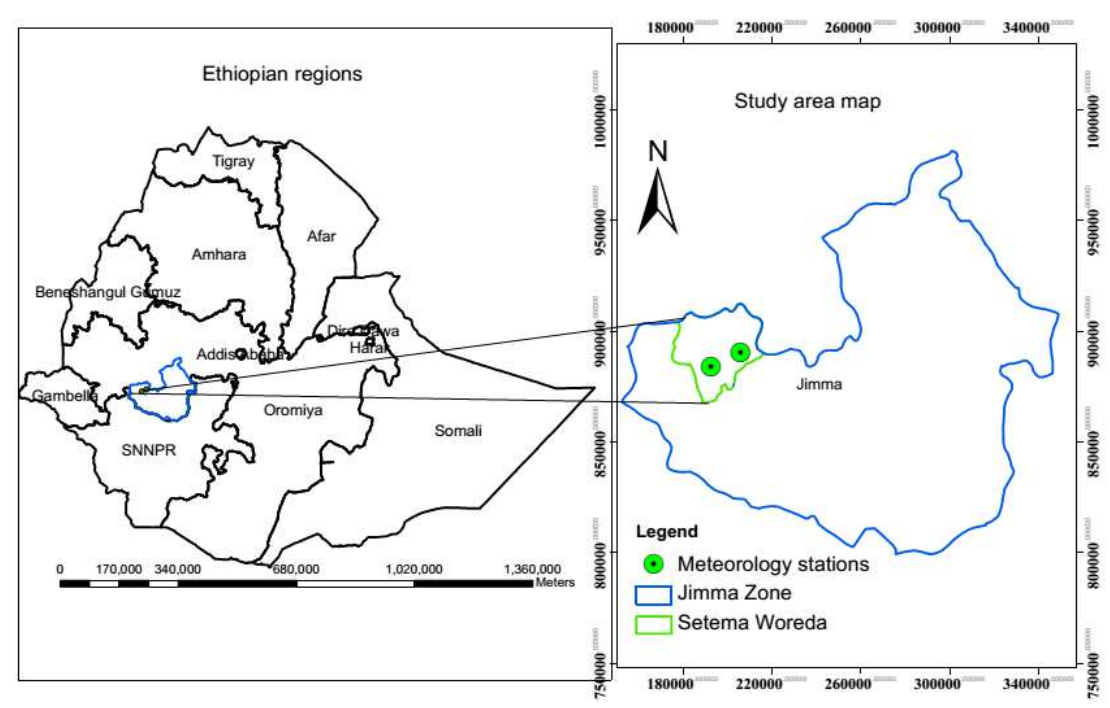

Figure 1. Study Area. 
Table 1. Representative Meteorology Station Site Histories.

\begin{tabular}{|c|c|c|c|c|c|c|}
\hline Stations & Region & Zone & Woreda & Latitude & Longitude & Altitude (m) \\
\hline Setema & Oromia & Jimma & Setema & $08^{0} 02.443^{\prime}$ & $036^{0} 19.956^{\prime}$ & 2116 \\
\hline Gatira & Oromia & Jimma & Gatira & $07^{0} 59.114^{\prime}$ & $036^{0} 12.945^{\prime}$ & 2361 \\
\hline
\end{tabular}

\subsection{Research Methodology}

In this study, annual and seasonal patterns of the rainfall are examined for two meteorological stations based on an inter-seasonal spread of rainfall: June- September (Gannaa), October-January (Birraa) and March to April (Bona). Daily rainfall record for the selected stations (Table 1) were obtained from Ethiopia National Meteorology Agency for the period of 1983-2013 for Gatira and 1979 -2011 for Setema. Monthly, seasonal and annual rainfalls were derived from the daily data of those stations. Data was used to analyze the trends and variability in rainfall for the stations.

Rainfall Trend and Variability Analysis

$$
\operatorname{sign}(x j-x i)=-1 \text { if }\left(\mathrm{x}_{\mathrm{j}}-\mathrm{x}_{\mathrm{i}}\right)<0,0 \text { if }\left(\mathrm{x}_{\mathrm{j}}-\mathrm{x}^{\mathrm{i}}\right)=0 \text { and }+1 \text { if }\left(\mathrm{x}_{\mathrm{j}}-\mathrm{x}_{\mathrm{i}}\right)>0
$$

Standardized rainfall anomaly index, rainfall concentration index and coefficient of variation were used as descriptors of rainfall variability. The rainfall variability for representative meteorological stations was determined by calculating the coefficient of variation (CV) as the ratio of the standard deviation to the mean rainfall in a given period $(\mathrm{CV} \%$, when expressed as a percentage) as used by [3]' and [2]. Standardized Anomaly Index was calculated as the difference between the annual total of a particular year and the longterm average rainfall records divided by the standard deviation of the long-term data. This characteristic of the SAI has contributed to its popularity for application drought monitoring and also makes possible the determination of the dry and wet years in the record [24]. Its formula is given as:

$$
Z=\frac{(x-\mu)}{\delta}
$$

Where $Z$ is standardized rainfall anomaly; $\mathrm{x}$ is the annual rainfall total of a particular year; $\mu$ is mean annual rainfall over a period of observation and $\delta$ is the standard deviation of annual rainfall over the period of observation. Standardized anomaly index value was categorized according to [16] classification (Table 2).

Table 2. SAI Value Classification Table.

\begin{tabular}{ll}
\hline SAI value & Category \\
\hline $2.0+$ & extremely wet \\
1.5 to 1.99 & very wet \\
1.0 to 1.49 & moderately wet \\
-.99 to. 99 & near normal \\
-1.0 to -1.49 & moderately dry \\
-1.5 to -1.99 & severely dry \\
-2 and less & extremely dry \\
\hline
\end{tabular}

Source: McKee (1993).

This study used also precipitation concentration index (PCI) to investigate heterogeneity of monthly rainfall [20].
In this particular study, Mann-Kendall's test was employed. Mann-Kendall's test is a non-parametric method, which is less sensitive to outliers [14]. Mann-Kendall's test checks the hypothesis of no trend versus the alternative hypothesis of the existence of increasing or decreasing trend.

$$
\mathrm{S}=\sum_{i-1}^{N-1} \sum_{J=I+1}^{n} \operatorname{sgn}(\mathrm{xj}-\mathrm{xi})
$$

Where $\mathrm{S}$ is the Mann-Kendal's test statistics; $x \mathrm{i}$ and $x \mathrm{j}$ are the sequential data values of the time series in the years $i$ and $j(j>i)$ and $N$ is the length of the time series.

$$
P C I=\frac{\left(\sum_{i-1}^{12}\right)}{\left(\sum_{i-1}^{12} \mathrm{pi}\right) 2} * 100
$$

Where pi is the monthly rainfall in month $i$

The seasonal scale of Rainfall Concentration Index was calculated using equation below

$$
x=\frac{\left(\sum_{i-1}^{\text {pi2 }}\right)}{\left(\sum_{i-1}^{3} \text { pi }\right) 2} * 25
$$

Annual and seasonal rainfall concentration index according to Oliver's classification 11: i. PCI $<10$ indicates uniform rainfall distribution (low rainfall concentration), ii. PCI $>11$ and $<15$ indicates moderate rainfall concentration; iii. PCI $>16$ and $<20$ indicates irregular distribution, iv. PCI $>20$ indicates a strong irregularity (i.e., high rainfall concentration) [20]. The main aims of analysis of annual and seasonal Precipitation Concentration Index (PCI) is to characterize spatial and temporal distribution of rainfall and PCI value of 16.7 will indicate that the total precipitation was concentrated in $1 / 2$ of the period and a PCI value of 25 will indicate that the total precipitation occurred in $1 / 3$ of the period [13]. Besides, farmers coping mechanism was indicated using mean and graphs.

\section{Result and Discussion}

\subsection{Annual and Seasonal Rainfall Trend Analysis}

The results of the statistical analysis at $95 \%$ confidence level for annual rainfall data using Mann-Keld test have both positive and negative trends. The results obtained for rainfall series indicated that Setema revealed negative trends while Gatira 
showed positive trends for annual rainfall series. Positive value of sen's slopes indicates an upward or increasing trend in Gatira, while Setema negative value of sen's slop gives a downward or decreasing trend in the time serious (Table 3).

Table 3. Annual rainfall trends for Gatira and Setema meteorological stations.

\begin{tabular}{lllll}
\hline Annual rainfall trends & & & & \\
\hline Stations & Trends & p value & Sen.'s slope & Mean \\
\hline Gatira & 0.187 & 0.145 & 5.089 & Standard deviation(mm) \\
Setema & -0.081 & 0.530 & -4.716 & 1928.456 \\
\hline
\end{tabular}

*=significant at $\mathrm{p}<0.05$

Annual rainfall trend analysis is not statistically significant. Findings from national and regional level rainfall trends analysis reported both increasing and decreasing trends [25], [3], [10] and [22]. According to [5] report, the significant decline in rainfall in southwestern Ethiopia was observed. Similarly, [22] reported that analysis of the historical rainfall records in North Central Ethiopia revealed that there has been a trend of decreasing rainfall. However, the trend analysis of annual rainfall showed that rainfall remained more or less constant when averaged over the whole country for 1951-2006 [19]. Other studies [21] confirmed regional variations can be much larger, and considerable spatial and temporal variations may exist between climatically different stations.

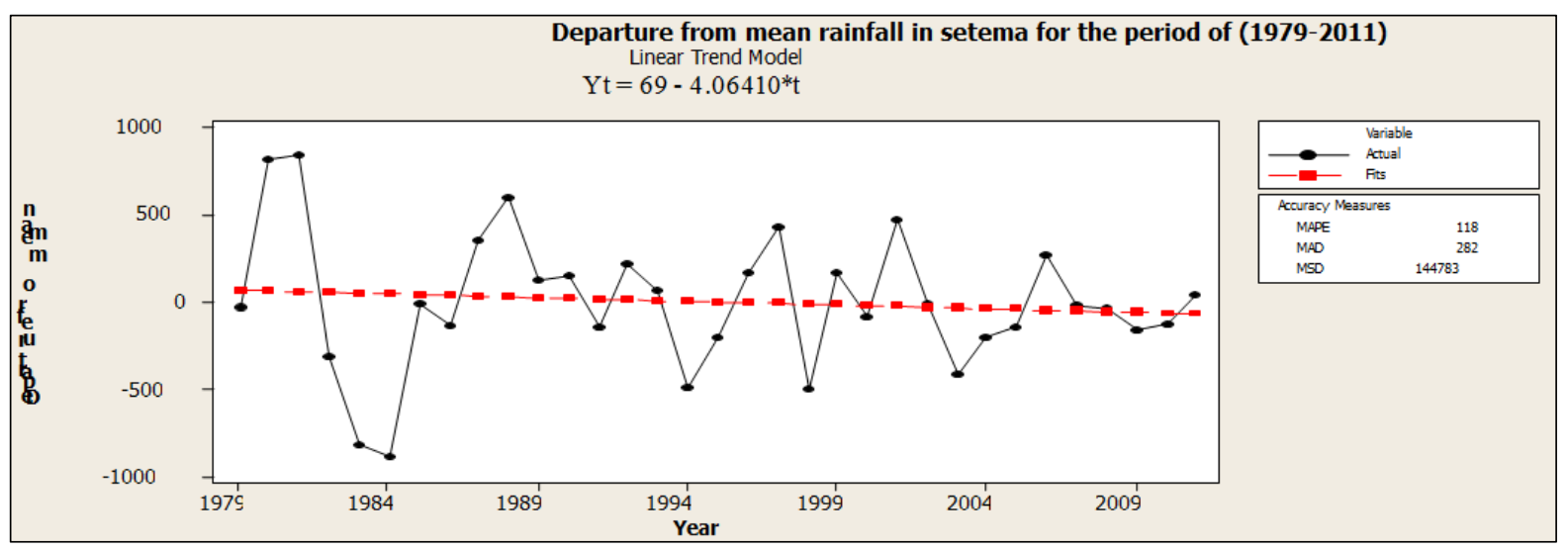

Figure 2. Departure from mean rainfall in Setema for the period of (1979-2011).

The deviation of annual mean temperature in Setema from 1979 to 2011 gives a strike indicator of change on climate in the study area (Figure 2). The main season (June to September) season revealed negative trends at Setema while positive at Gatira. These seasons were contributed largest amount of rainfall to annual series (Table 3). Similarly, seasonal rainfall trend analysis results for March to May season showed a negative trend in Setema (Table 4). However, analysis of seasonal rainfall trend analysis for the period of (1981-2011) shows rising trend for March to April at Gatira and the trend is statistically significant. Rising trends of March to April rainfall will provide moisture for main season land preparation.

Table 4. Seasonal rainfall trends for Gatira, Jimma and Setema metrological stations.

\begin{tabular}{|c|c|c|c|c|c|c|c|c|c|}
\hline \multirow[t]{2}{*}{ Stations } & \multicolumn{3}{|c|}{ Main season (June to September) } & \multicolumn{3}{|c|}{ Bona (March to April) } & \multicolumn{3}{|c|}{ Birraa (October-January) } \\
\hline & Trend mm/year & P-value & Sen's slope & Trend mm/year & P-value & Sen's slope & Trend mm/year & P-value & Sen's slope \\
\hline Gatira & 0.05 & 0.71 & 0.94 & $0.05^{*}$ & 0.71 & 0.94 & & & \\
\hline Setema & -0.08 & 0.51 & -2.42 & -0.05 & 0.68 & -1.40 & 0.011 & 0.939 & 0.018 \\
\hline
\end{tabular}

$*=$ significant at $\mathrm{p}<0.05$

\subsection{Rainfall Variability Analysis}

The annual weighted average rainfall for studied stations is $1796.5 \mathrm{~mm}$. spatially mean annual rainfall of study area is ranged from $1665 \mathrm{~mm}$ in Setema to $1928 \mathrm{~mm}$ Gatira (Table 5). The main rainy season (June to September) contributes 52 to $60 \%$ to the annual rainfall totals while March to April season rainfall also contributes 25 to $30 \%$ to the annual rainfall (Table 5). The main (long) rainy season (June-September) total mean rainfall ranges between $1045 \mathrm{~mm}$ and $1010 \mathrm{~mm}$.

\subsubsection{Coefficient of Variation}

The coefficient of variation in stations revealed that rainfall in the region has low inter-annual variability (Table 5). The result indicated that rainfall variability at Setema $(\mathrm{CV}=23 \%)$ while Gatira $(\mathrm{CV}=8 \%$ ). Main season (June to September) rainfall contributed the highest Percentages (52-60\%) of rainfall to annual rainfall and March to April season rainfall also contributes $25 \%$. This result agreed with the findings of [11] who reported that main seasons were contributed the 
highest contribution to annual rainfall in the country.

Table 5. Annual and seasonal rainfall variability (coefficient variation) for Gatira and Setema.

\begin{tabular}{lllllllll}
\hline \multirow{2}{*}{ Stations } & Annual & \multicolumn{4}{c}{ Main season (June to September) } & \multicolumn{3}{c}{ Bona(March to April) } \\
\cline { 2 - 9 } & Mean & CV & Mean & \% & CV & Mean & \% & CV \\
\hline Gatira & 1992 & 8.1 & 1045.3 & 52.5 & 24 & 526.1 & 26.4 & 38.5 \\
Setema & 1665.2 & 23.6 & 1010.1 & 60.6 & 38.5 & 419.6 & 25 & 63.2 \\
\hline
\end{tabular}

Moreover, main season (Gannaa) rainfall coefficient variation was range 24 at Gatira while 38.5 at Setema (Table 5). In line with other studies in Ethiopia, [4] reported that high coefficient variation in annual, main season $(\mathrm{CV}$ 30\%) and March to April (CV 50\%) in northern Ethiopia. Moreover, [3] who reported that inter-annual rainfall coefficient variation (18-40\%), main season (CV 17 to $39 \%$ ) and March to April (CV 27 to 57\%) for rift valley of Ethiopia which is high annual variability as compared to this study. The analysis of coefficient of variation for March to April (Bona) season variability in this region is higher than main season rainfall which agreed with many others authors [3] and [4]. These suggest, inter-annual and annual variability in rainfall distribution was influenced agriculture activities in the study area which was totally rainfall dependent. Small change on in amount and distribution of main season (June to September) rainfall could be negatively influence crop production which is already impacted by the current climate variability, is likely to be further challenged with future climate change.

\subsubsection{Rainfall Concentration Index}

The Rainfall Concentration Index values for the annual and seasonal rainfall were calculated based on the equations. The analysis result indicted that the rainfall concentration index (PCI) value is range 12 to 18 for most of the stations. The rainfall concentration index calculated at annual level showed values $>16$ in the Setema station which is moderate rainfall irregularity (Table 6). Rainfall concentration index (PCI) values of less than 10 indicated uniform monthly distribution of rainfall, values between 11 and 20 indicate high concentration, and values above 21 indicate very high concentration [20].

Table 6. Annual and seasonal rainfall index for Gatira and Setema stations.

\begin{tabular}{lllllll}
\hline \multicolumn{7}{c}{ Annual and seasonal PCI } \\
\hline stations & $<\mathbf{1 0}$ & $<\mathbf{1 6}$ & $>\mathbf{1 6}$ & $\mathbf{\%}$ of years above 16 PCI & Keremt PCI & Belg PCI \\
\hline Gatira & 0.0 & 30.0 & 0.0 & 0 & $25-26$ & $33-48$ \\
Setema & 0.0 & 17 & 6 & 35 & $25-41$ & $46-66$ \\
\hline
\end{tabular}

On the contrary, [2] reported that moderate to high interannual rainfall concentration in Amahara region and similarly Belay (2014) study revealed that there is moderate to high in Central Rift Valley in Ethiopia. Furthermore, [4] reported that high and very high concentration in Northern Ethiopia (Tigray) which indicates poor monthly distribution of the rainfall. The lowest value of PCI $(<10)$ indicating the perfect uniformity in precipitation distribution or same amount of precipitation occurs in each month of year. It can be concluded that study area range moderate to high monthly rainfall concentration which implies that total rainfall of the study area concentrated in $1 / 2$ of the period (Table 6).

\subsubsection{Standardized Anomaly Index (SAI)}

Analysis of the standard anomaly index for the stations is presented (Table 7). This study used SAI to demonstrate the intensity and frequency of drought and inter-annual variation at various time scales and area. The negative anomalies of Gatira station were $48 \%$ during the period of 1983-2013. In Setema, 52\% of years were revealed negative anomalies over the period of 1979 to 2011. The differences between the frequencies of occurrence of the dry and wet years range of the studied area were the small difference. Negative anomaly index (dry) was observed in 1983, 1984, 1994, 2002, and 2003 in all stations (Figure 3 and 4). In line with this Quinn and Neal (1987) and Webb and Braun (1994) cited in [19] reported that Ethiopia experienced drought years in 1983-1984, 1987-1988, 1990-1992, 2000, and 2002/2003.

This study indicated that standard anomaly values of $(-2$ or less) categorized as extreme drought has occurred in 1983, 1984, 1994, 1998, and 2008 years in Setema. The result showed that 2009 and 2008 were the driest years in setema (Appendix Table 1). In agreement with this finding [11] also found that nationally, 2009 was the second driest year, surpassed only by the historic year 1984. Moreover, severe drought period standard anomaly values (SAI value 1.5 to -1.99$)$ observed in 2003 in Setema. On other hands severe wet (SAI value of +1.5 to +1.99 ) period occurred 1987 and 1992 in Setema and extreme severe wet period occurred 1980 (SAI value 3.21) and 1981 (SAI value 3.84). However, there are no observed extreme and severe drought characteristics in Gatira over the period of 1981-2013 (Table 7). 
Table 7. Standardized Rainfall Indices with the Frequency and Percentages of occurrence over the period of 1979 to 2011 in the Setema and Gatira (19812011).

\begin{tabular}{lllll}
\hline & & \multicolumn{2}{l}{ Percentage and frequency of occurrence (Years) } \\
\cline { 2 - 5 } Drought category & Standard anomaly index value range & Setema & Gatira \\
\cline { 2 - 5 } & & Frequency & \% & Frequency \\
\hline Extreme Drought & -2.0 or Less & 5 & 15.15 & 0.00 \\
Severe Drought & -1.5 to -1.99 & 2 & 6.06 & 0.00 \\
Moderate Drought & -1.0 to -1.49 & 2 & 6.06 & 0.00 \\
Mild Drought & -0.99 to 0 & 8 & 24.24 & 15 \\
Normal & +0.01 to +1.49 & 9 & 30.30 & 16 \\
Severe Wet & +1.5 to +1.99 & 1 & 3.03 & 0 \\
Extreme Wet & +2.0 or more & 5 & 15.15 & 0.00 \\
\hline
\end{tabular}

This is in harmony with the findings of [19] who reported that increased dry year frequency in Ethiopia. The rainfall pattern in the studied stations showed the characteristics that a dry year is followed by another two or three dry years and visà-vis for the wet years (Figure $3 \& 4$ ). In fact, that the mean annual rainfall in studied station exceeds $1737.9 \mathrm{~mm}$ which is greater than result in other part of Ethiopia [10]. Further, [23] reported that Ethiopian mean annual rainfall range more than (2,700 millimeters) occurs in the southwestern highlands to less than 100 millimeters in northeast.

The present study revealed rainfall fluctuation was occurred both in annual variability (Table 5) and inter-annual variability. Such inter-annual variability problems in rainfall would negatively affect the ability of farmers to cope with climate change and variability [2]. Similarly, [7] reported that in next few decades and the second half of the 21 st century and beyond, Risk of food insecurity and the breakdown of food systems linked to warming, drought, flooding, and precipitation variability and extremes, particularly for poorer populations in urban and rural settings. It is obvious that drought phenomenon will create a more vulnerable environment for the subsistence farming sector.

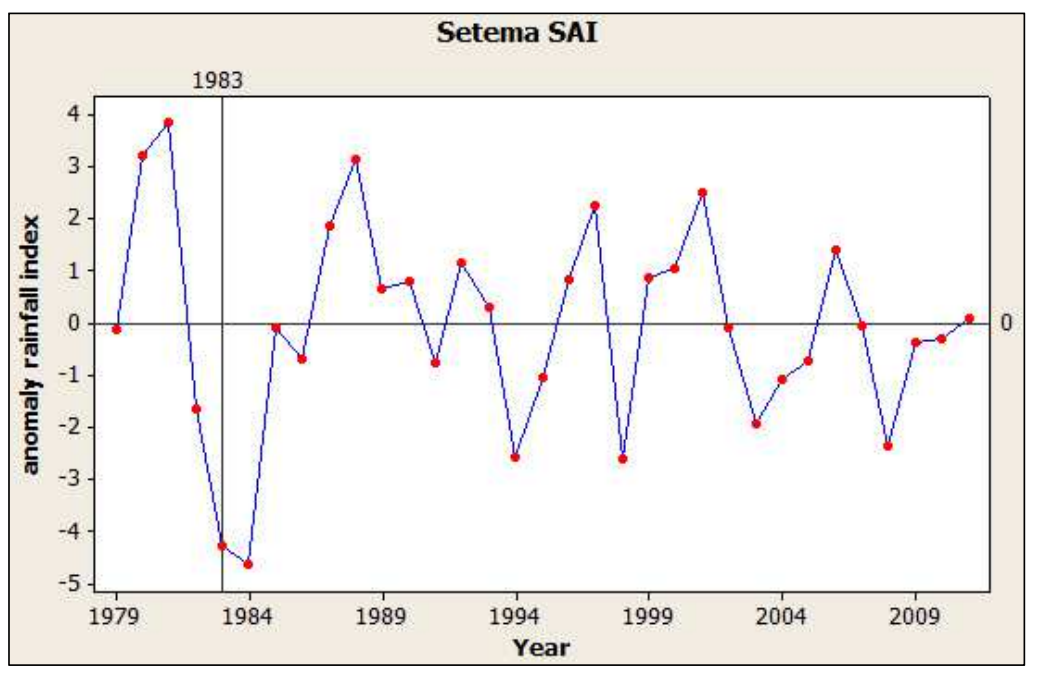

Figure 3. Setema Standard anomaly index over the period of (1979-2011).

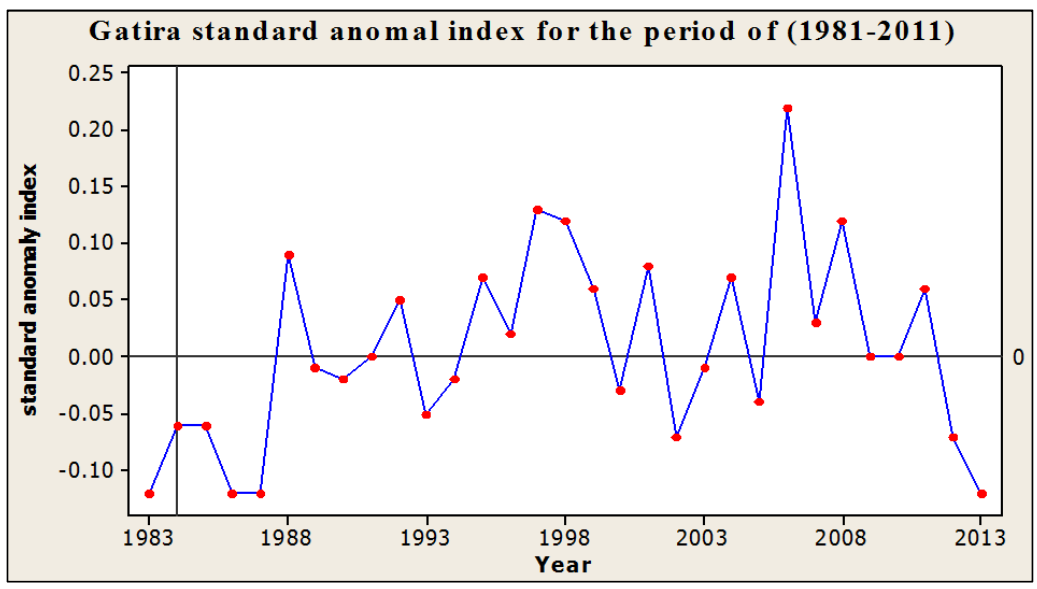

Figure 4. Gatira standard anomaly index over the period of (1981-2011). 


\subsection{Climate Change Adaptation Strategy}

Different types of coping strategy were found from the study area at household and community level. The coping strategies being used by farmers in response to climate shock to drought and erratic rainfall. Farmers were asked if they had experienced any climate-related shocks over the past ten years and their response to perceived climate change impacts. The main shocks were from erratic rainfall and below average rainfall which results in decline crop yield. In response to drought shocks, sold livestock as a main coping strategy (Figure 5).

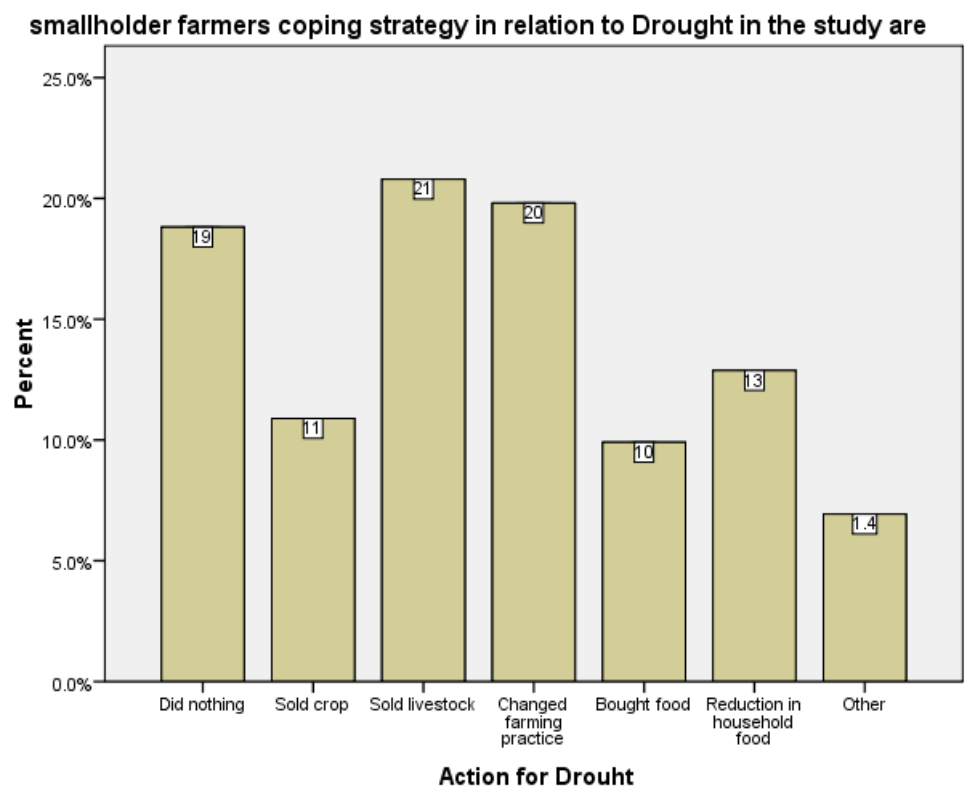

Figure 5. Smallholders' farmer's coping mechanism in relation to drought.

Household coping strategies vary depending on the hazard experienced (Figure 6 \& Figure 5). The present studies showed that selling livestock is widely used to deal with drought (Figure 5) and were as changing farming practices widely used in response to erratic rainfall (Figure 6). Farmers are modifying their practices in order to mitigate with climate change and variability. This shows that they are aware of the changing climatic conditions. Moreover, Local community stated that responses to sudden climate shock e.g. to crop failure were sold livestock which is impossible for resourcepoor farmers. Resource-poor farmers also involve attempts the production of timber and charcoal from the local forest for local and more remote markets as an important coping strategy in the area. Local community indicated coffee farm and livestock is an important form of security during especially the crop failure.

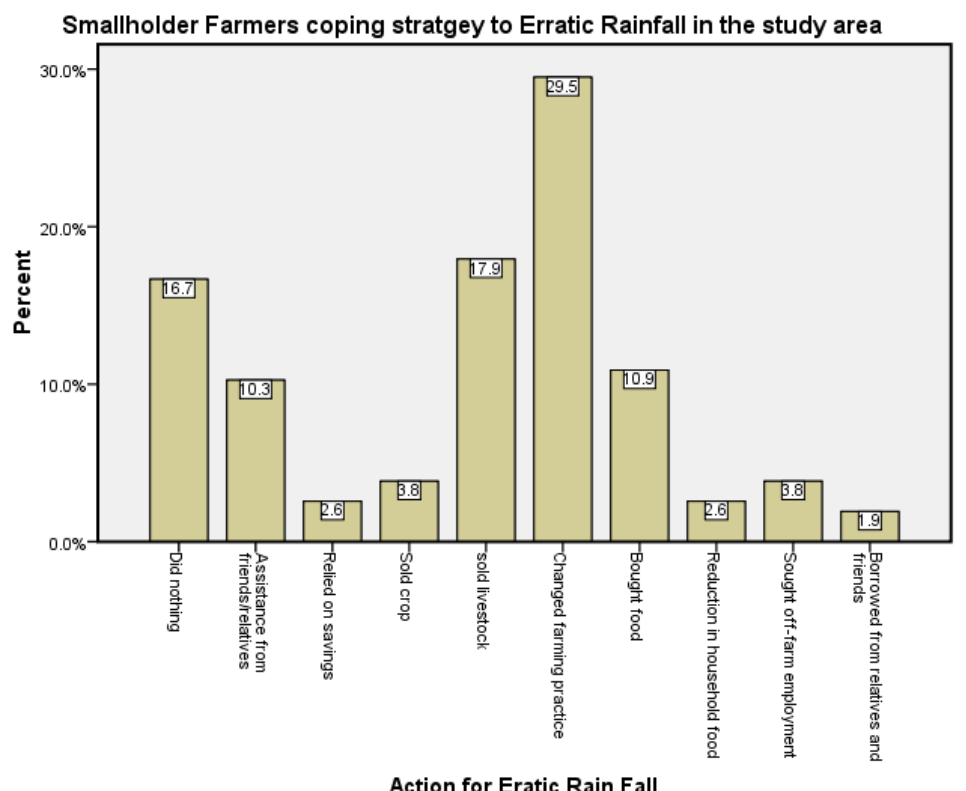

Action for Eratic Rain Fall

Figure 6. Small holder farmers response in relation to erratic rainfall. 


\section{Conclusion}

This study was undertaken to understand rainfall variability and farmers coping mechanism in Jimma, southwestern Ethiopia. The study employed Mann-Kendall's test to detect a change in rainfall trends. Results for rainfall trend analysis for Setema indicated decreasing trends, while Gatira revealed increasing trends. Overall, the observed trends were not statistically significant. The Coefficient of variation revealed that rainfall in the region has low interannual variability as compared to studies done over other parts of Ethiopia. The standardized anomalies of annual rainfall revealed negative anomalies $42 \%$ at Setema, 52\% over 1979-2011 at Jimma during 1990-2013 and 50\% of years at Gatira during 1983-2013. All most of both stations annual rainfall has shown negative anomalies for much of the 1983/4 and 1994. Regarding coping mechanism, farmers are modifying their practices in order to mitigate with climate change and variability mainly includes selling livestock, changing and farming practice. The present demonstrated rainfall trend and variability analysis for two meteorological stations in southwestern part of the Ethiopian and farmers response to such variability, however, a comparison was done with the result from nationwide and different data ranges. These will provide information on rainfall variability of the districts and could be used as input for the local adaptation planning and to develop adaptation strategies of the study areas.

\section{Acknowledgements}

Grateful to CHIESA (Change Impacts on Ecosystem Services and Food Security in Eastern Africa) project coordinated by the International Center of Insect Physiology and Ecology (ICIPE) in Nairobi, Kenya, to provide financial support to research and grateful to Ethiopian National Meteorology Agency for providing rainfall data for this study.

\section{References}

[1] Aghajani Gr (2007). Agronomic analysis of chartertics of the rainfall case study of Iran pakistan journal of biological science 10(8):1354-1359.

[2] Ayalew D, Tesfaye K, Mamo G, Yitaferu B, Bayu W (2012). "Variability of rainfall and its current trend in Amhara region, Ethiopia.” African Journal of Agricultural Research, 7(10): 1475-1486.

[3] Belay $T$ (2014). Climate variability and change in Ethiopia:Exploring impacts and adaptation options for cereal production. Production Ecology and Resource Conservation, Wageningen University. Doctoral 16. Wageningen University.

[4] Hadgu G, Tesfaye K, Mamo G, Kassa B (2013). "Trend and variability of rainfall in Tigray, Northern Ethiopia: Analysis of meteorological data and farmers' perception." Academia Journal of Environmental Sciences 1(8): 159-171.
[5] Hagos F, Awulachew SB, Makombe G, Namara RE, B (2009). Importance of irrigated agriculture to the Ethiopian economy: Capturing the direct net benefits of irrigation. Int. Water Manage. Inst. pp. 37. (IWMI Research Report).

[6] Gebreegziabher, Z., J. Stage, A. Mekonnen, and A. Alemu (2011). Climate Change and the Ethiopian Economy A Computable General Equilibrium Analysis Environment for Development.

[7] Inter-governmental Panel on Climate Change (IPCC) (2014a). Adaptation Needs and Options; A. Patt and K. Takeuchi_WGII AR5 Chapter 14.

[8] Jain S. K, Kumar V, Saharia M (2012). Analysis of rainfall and temperature trends in northeast India International Journal of Climatology Int. J. Climatol. (2012) Published online in Wiley Online Library (wileyonlinelibrary.com) DOI: 10.1002/joc.3483

[9] Jimma Zone Agricultural Office (JZAO) (2013). Annual report of Jimma one agricultural office Oromia, Ethiopia.

[10] Kebede D, Adane H (2011). Climate change adaptations and induced farming livelihoods. Drylands Coordination Group

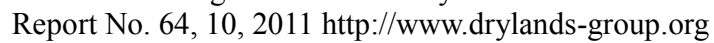

[11] Koricha D, Viste E, Sorteberg A (2012). Recent drought and precipitation tendencies in Ethiopia Theory Applied Climatology 2013 112:535-551 DOI 10.1007/s00704-0120746

[12] Krishan G, Pankaj G, Rao M. s,. Kumar C. P, Rajesh (2014). Aggarwal rainfall trend analysis in Saharanpur District of Uttar Pradesh-Agricultural Context.

[13] Luis M, Gonz'alez-Hidalgo J. C, Brunetti M, Longares L. A (2011). Precipitation concentration changes in Spain,19462005 www.nat-hazards-earth-syst-sci.net/11/1259/2011/ Nat. Hazards Earth Syst. Sci., 11, 1259-1265, 2011, Spain

[14] Mann HB (1945). Nonparametric tests again trend. Econometrica 13: 245-259.

[15] McKee T. B, Doesken N. J, Kleist D (1993). The relationship of drought frequency and duration to time scale. In: Proceedings of the Eighth Conference on Applied Climatology, Anaheim, California, 17-22 January 1993. Boston, American Meteorological Society, 179-184.

[16] Meybeck, A., J. Lankoski, S. Redfern, N. Azzu, V. Gitz (2012). Building resilience for adaptation to climate change in the agriculture sector. Proceedings of a Joint FAO/OECD workshop, food and agriculture organiztion

[17] McSweeney, C., New, M., and Lizcano, G (2008). United Nation Development Programme (UNDP) Climate Change Country Profiles - Ethiopia Available at http://countryprofiles.geog.ox.ac.uk.

[18] National Meteorological Agency of Ethiopia (NMA) (2006). National Adaptation Programme of Action of Ethiopia (NAPA). National Meteorological Agency, Addis Ababa. Ethiopia.

[19] National Meteorological Agency of Ethiopia (NMA) (2007). Climate Change National Adaptation Programme of Action (Napa) Of Ethiopia. The Federal Democratic Republic Of Ethiopia Ministry of Water Resources National Meteorological Agency. Abebe T., National Meteorological Agency. Addis Ababa. 
[20] Oliver JE (1980). Monthly rainfall distribution: a comparative index. Professional Geographer 32: 300-309.

[21] Parry M. L, Canziani O. F, Palutiko J. P, V Linden V, Hanson C. E (2007). Technical Summary. Climate Change 2007: Impacts, Adaptation and Vulnerability. Contribution of Working Group II to the Fourth Assessment Report of the Intergovernmental Panel on Climate Change,. IPCC_Technical report. UK, Cambridge University Press: 23-77.

[22] Roa P, Solomon A (2013). "Trend Analysis And Adaptation Strategies of Climate Change In North Central Ethiopia." International Journal of Agricultural Science and Research (IJASR) 3, Issue 1, Mar 2013, 253-(2) 62.
[23] World Bank (2003). Ethiopia: Managing water resources to maximize sustainable growth.

[24] World Metrology Organization (WMO) (2012). Standardized Precipitation Index User Guide WMO-No. 10907 ISBN 97892-63-11091-6

[25] Wing H. Cheung, Gabriel B. Senay and Ashbindu Singh (2008). Trends and spatial distribution of annual and seasonal rainfall in Ethiopia, INTERNATIONAL JOURNAL OF CLIMATOLOGY Int. J. Climatol. 28: 1723-1734 (2008) Published online 5 March 2008 in Wiley Inter Science, DOI: $10.1002 /$ joc. 1623

[26] http://www.meteo-ethiopia.net/climate.htm October 2014 